\title{
Distribuição sazonal e horária das precipitações em Caraguatatuba-SP e a ocorrência de eventos extremos nos anos de 2007 a 2011
}

\author{
Seasonal and time distribution of rainfall in Caraguatatuba-SP and extreme events \\ occurring in the years 2007 to 2011
}

\author{
Denise Dias dos Santos ${ }^{1}$, Emerson Galvani ${ }^{2}$ \\ ${ }^{1,2}$ Universidade de São Paulo, SP, Brasil
}

\begin{abstract}
Resumo
A precipitação é o atributo climático de maior importância quando se pretende estudar regiões tropicais. O regime chuvas na região de Caraguatatuba, Litoral Norte de São Paulo é influenciado pela latitude, umidade proveniente do oceano e pela Serra do Mar, proporcionando precipitações resultantes do efeito orográfico e alterando o deslocamento de sistemas frontais. Este estudo realizou uma análise da sazonalidade das precipitações e da distribuição horária, nos anos de 2007 a 2011, verificando a presença de eventos extremos, superiores a $40 \mathrm{~mm}$ em 24 horas, neste período. Utilizou-se de um conjunto de dados disponibilizados pelo Sistema Nacional de Dados Ambientais (SINDA/INPE), Boletins Climanálise, imagens de satélite e cartas sinóticas. Os resultados mostram que as chuvas concentram-se no fim da tarde e início da noite no período do verão. O deslocamento dos sistemas frontais se dá ao longo do dia e a duração das precipitações ocorre de acordo com a intensidade dos sistemas, durante o período do outono. Na série temporal avaliada, ocorreram nove eventos com chuvas acima dos $40 \mathrm{~mm}$ diários: seis no verão e três no outono. No verão esses eventos extremos estavam associados à Zona de Convergência do Atlântico Sul (ZCAS) e no outono associados aos sistemas frontais. Sazonalmente, as precipitações ocorrem em média $64,4 \%$ na primavera e verão e $35,6 \%$ no outono e inverno.
\end{abstract}

Palavras-chave: Precipitação, sazonalidade, eventos extremos.

\begin{abstract}
Precipitation is the most important climate attribute in studying tropical regions. The rainfall regime in the region Caraguatatuba, North Coast of São Paulo is influenced by latitude, humidity coming from the ocean and the Serra do Mar, providing precipitation resulting from the orographic effect and changing the offset frontal systems. This study aims to analyze the seasonality of rainfall and time distribution, in the years 2007 to 2011, verifying the presence of extreme events, higher than $40 \mathrm{~mm}$ in 24 hours, in this period. We used a set of data provided by the Sistema Nacional de Dados Ambientais (Sinda/INPE), Bulletins Climanálise, satellite pictures and synoptic charts. The results show that the rains are concentrated in the late afternoon and early evening in the summer period. The displacement of the frontal systems occurs through the day and duration of the rainfall takes place according to the intensity of the systems during the autumn period. Time series evaluated, there were nine events with rainfall above $40 \mathrm{~mm}$ daily, six in summer and three in the autumn. In summer these extreme events were associated with South Atlantic Convergence Zone (SACZ) and in the autumn associated with frontal systems. Seasonally, precipitation occurs on average $64.4 \%$ in spring and summer and $35.6 \%$ in autumn and winter.
\end{abstract}

Keywords: Rainfall, seasonality, extreme events 


\section{INTRODUÇÃO}

Para o estudo de atributos climáticos em uma determinada localidade faz-se necessário analisar o contexto em que eles estão inseridos, não somente com características locais, mas também considerando a circulação geral da atmosfera. Em uma região tropical, por exemplo, o atributo climático de maior relevância é a precipitação, que pode definir os períodos de secas e de chuvas (GALVANI et al., 1998).

A precipitação é importante quando se pretende estudar diversos temas em Geografia Física. Por exemplo, conhecendo-se o regime pluviométrico de uma determinada área, é possível realizar detalhados trabalhos de gabinete sobre seu relevo, vegetação e solo antes da realização do trabalho de campo; os dados de chuvas também serão importantes para embasar as análises realizadas posteriormente. Em se tratando de Planejamento Ambiental, as precipitações intensas são um fator de influência na ocupação do espaço rural e urbano. Sentelhas et al (1998), observando a carência de informações sobre as chuvas horárias intensas de curta duração, faz uma análise para o município de Piracicaba (SP). Pezzopane et al (1995) seleciona três locais no estado de São Paulo (Campinas, Pindorama e Ubatuba) para caracterizar o total e a frequência horária das precipitações servindo como subsídio ao planejamento agrícola.

No Litoral Norte Paulista, fatores como a latitude, o relevo e a alta umidade que se desloca do oceano para o continente podem interferir no clima local. Tal configuração proporciona uma distribuição das chuvas peculiar, em que não é possível estabelecer uma estação seca e há a ocorrência de eventos extremos. Estes eventos podem ocorrer em várias escalas de tempo, de diária a mensal e sazonal (CAVALCANTI, 2012). As inundações e deslizamentos ocorrem quando, principalmente em área urbana, os excessos de chuvas (relacionados a células convectivas profundas, muitas vezes embutidos em sistemas sinóticos que podem persistir sobre a área) são combinados com alta impermeabilização do solo e ocupação em áreas de alta susceptibilidade aos escorregamentos, causando perdas e danos não somente materiais, mas também humanos.

Para o município de Caraguatatuba (SP), área definida para o estudo, é fundamental compreender a importância do efeito orográfico na gênese do clima do Litoral Norte Paulista. A orografia influencia na chegada e deslocamento de umidade e massas de ar que definem o tipo de tempo do local. Segundo Sant'Anna Neto (1990), a estrutura do relevo da enseada de Caraguatatuba impulsiona o efeito de formação de chuvas orográficas e dificulta o deslocamento da Frente Polar Atlântica (FPA) na área. A região Sudeste do Brasil caracterizase por ser uma zona de transição entre climas quentes de latitudes baixas e climas mesotérmicos de latitudes médias (BORSATO; SOUZA FILHO, 2008). Portanto, a área de estudo está sob influência de sistemas frontais intensos oriundos das altas latitudes, mas também costuma apresentar valores de temperatura próximos aos encontrados nas baixas latitudes; aliada a umidade do oceano e disposição do relevo, a região é caracterizada pela alta pluviosidade.

Estatisticamente, um evento é considerado extremo quando está acima ou abaixo da média de um conjunto de dados. Considerando a chuva, que é um elemento eventual, os valores de precipitação que não se encontram dentro do intervalo da normal climatológica ou dos valores médios de uma determinada série histórica podem ser considerados como eventos extremos. Para o Litoral Norte Paulista a Defesa Civil estabelece que o acumulado de chuva igual ou superior a $120 \mathrm{~mm}$ em três dias determina o alerta para o plano de contingência. Segundo Tavares (2012), "para cada lugar, o suporte físico, tipo de uso e ocupação do terreno, determinam quanto a intensidade da chuva pode se tornar um desastre".

O objetivo deste trabalho é analisar a distribuição sazonal e horária das precipitações em Caraguatatuba-SP e identificar, por meio das frequências, a ocorrência de eventos extremos nos anos de 2007 a 2011.

\section{MATERIAIS E MÉTODOS}

\section{1 Área de Estudo}

O município de Caraguatatuba é uma das quatro cidades que compõem o Litoral Norte Paulista; localiza-se entre as latitudes $23^{\circ} 28^{\prime} \mathrm{S}$ e $23^{\circ} 46^{\prime} \mathrm{S}$ e as longitudes $45^{\circ}$ $16^{\prime} \mathrm{W}$ e $45^{\circ} 43^{\prime} \mathrm{W}$, com $485 \mathrm{~km}^{2}$ de área e 100.840 habitantes, segundo o Instituto Brasileiro de Geografia e Estatística (IBGE, 2010). Segundo Cruz (1986), a Serra do Mar, compartimento geomorfológico de extrema importância neste estudo, possui embasamento pré-cambriano, com contatos litológicos diferenciados e cicatrizes de origem tectônica; é formada por uma associação de vertentes escarpadas que fazem a divisão do planalto. As áreas costeiras são definidas pelo litoral e suas planícies, formando um sistema cujas inter-relações devem ser consideradas nas pesquisas, análises e planejamentos sobre este espaço.

Segundo a classificação climática de Köppen, que considera as médias de temperatura e precipitação anual, sazonal e dos meses extremos, observando também aspectos biogeográficos de cada região (SANT' ANNA NETO, 2013), o município recebe é classificado como Af (Clima Tropical Chuvoso), sem estação seca com a precipitação média do mês mais seco superior a $60 \mathrm{~mm}$. As temperaturas mínima e máxima do ar são de $18,2^{\circ} \mathrm{C}$ e $31,6^{\circ} \mathrm{C}$ (com a média em $24,9^{\circ} \mathrm{C}$ ), respectivamente, e a média anual de chuva é de 1757,9 mm (CEPAGRI, 2013). Silva et al (2005) destacam que no litoral norte não há uma estação seca definida; durante a primavera e o verão, os totais pluviométricos podem ultrapassar os 2000 $\mathrm{mm}$, no inverno e outono esse valor fica próximo aos 500 


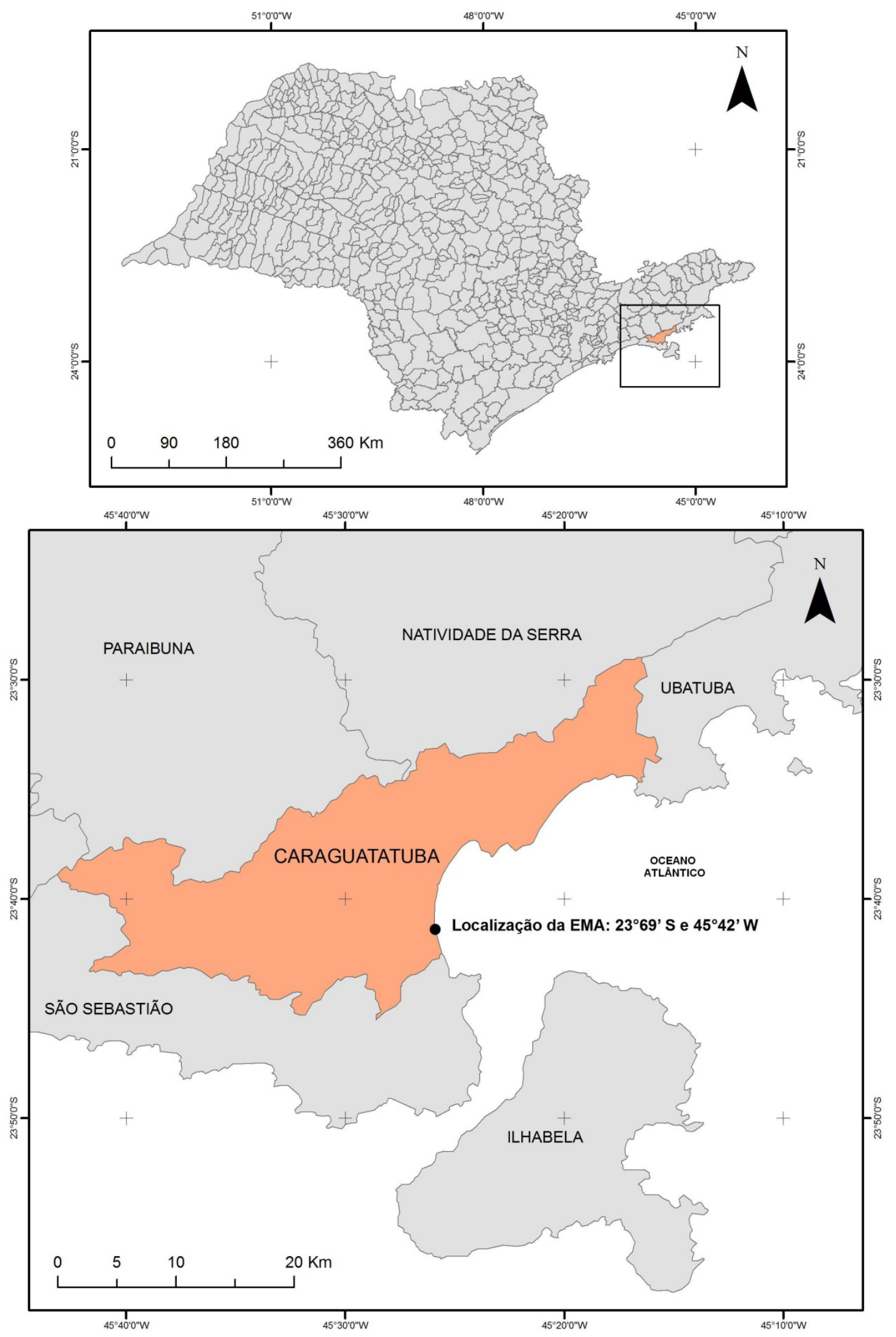

Figura 1: Localização do município de Caraguatatuba no estado de São Paulo. 
$\mathrm{mm}$, comprovando que há somente uma diminuição nos totais de precipitação durante estas estações.

Milanesi (2007) afirma que o regime de chuvas orográficas é determinado por diversos fatores de escala espacial e temporal, porém o maior responsável pelo desenvolvimento destas precipitações são os fluxos de ar, presentes nos sistemas atmosféricos regionais, pela brisa marítima e pela instabilidade atmosférica local que gera convecção. Em seu estudo sobre a normalidade da pluviometria no setor serrano de Cubatão na Baixada Santista, Nunes (1992), constata que a região apresenta "alguns dos montantes (de pluviosidade) mais altos do país, fruto da dinâmica atmosférica regional aplicada sobre um relevo escarpado".

A eleição da área de estudo justifica-se pelo fato de que as condições geomorfológicas da região, bem como sua proximidade do oceano, responsável por oferecer grande parte da umidade, proporcionam à área um conjunto de fatores que devem ser objeto de um estudo climatológico envolvendo a orografia e precipitações pluviais (CONTI, 1975).

\subsection{Obtenção dos Dados de Precipitação}

Para a realização deste trabalho, foram adquiridos dados secundários da Plataforma de Coleta de Dados (PCD) fornecidos pelo Sistema Nacional de Dados Ambientais (SINDA), órgão de responsabilidade do Instituto nacional de Pesquisas Espaciais (INPE). A estação meteorológica automática (EMA) está localizada na latitude $23^{\circ} 69^{\prime} \mathrm{S}$ e longitude $45^{\circ} 42^{\prime} \mathrm{W}$, em uma altitude de 3 metros acima do nível do mar, no bairro Porto Novo e transmite os dados coletados via satélite. Deve-se considerar que os dados obtidos através da EMA refletem a realidade geográfica do ambiente: ela está instalada em um bairro residencial, aproximadamente a 200 metros da praia, cercada por vegetação que alcança até um metro de altura.

Para análise, foram selecionados os dados diários compreendidos entre janeiro de 2007 e dezembro de 2011; os valores correspondem ao valor acumulado de precipitação (em $\mathrm{mm})$ a cada três horas $(00 \mathrm{~h}, 03 \mathrm{~h}$, 06h, 09h, 12h, 15h, 18h, 21h e 00h). Segundo o Instituto Nacional de Pesquisas Espaciais (INPE), a estação possui um acumulador digital para a gravação dos dados pluviométricos.

“Ele (o acumulador) é inicializado automaticamente quando atinge o limite de 4095 ou 2047 ou 655 mm (dependente da versão do software de coleta das PCDs) ou a qualquer tempo quando a PCD recebe visita de manutenção ou todo primeiro dia de cada mês às $00 \mathrm{~h} 00 \mathrm{~min}$ para a última versão do software de coleta das PCDs Meteorológicas".

Devido as possíveis falhas no equipamento, 1,1\% do total de observações do banco de dados apresentaram erros que foram corrigidos segundo a metodologia de coleta da PCD. Os dados foram trabalhados para a definição da distribuição sazonal e horária, bem como definir as frequências das precipitações no período. A identificação e análise dos eventos foram realizadas a partir dos gráficos, com o auxílio dos Boletins Climanálise e imagens de satélite (ambos disponibilizados pelo Centro de Previsão de Tempo e Estudos Climáticos - CPTEC do INPE) e cartas sinóticas da Marinha do Brasil.
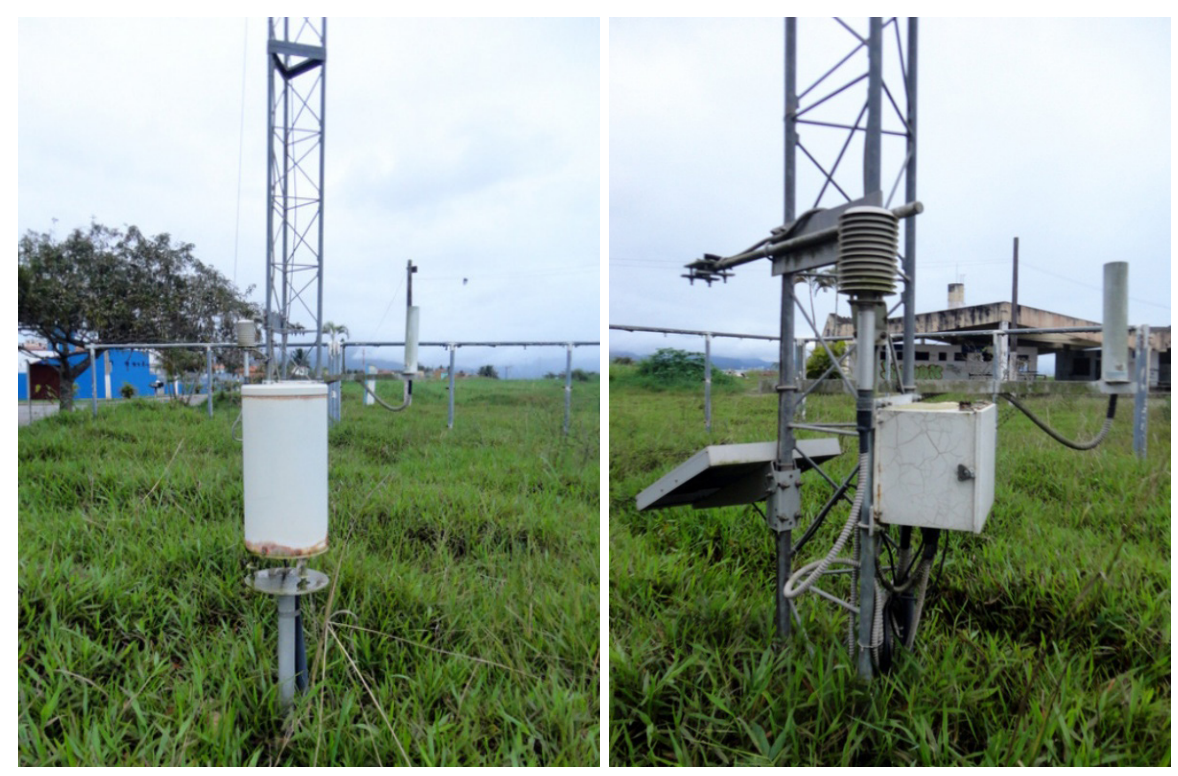

Figura 2: PCD 32521 - Caraguatatuba, localizada no bairro do Porto Novo: pluviômetro utilizado para coleta da precipitação acumulada e demais equipamentos da EMA. Azimutes $340^{\circ}$ (Noroeste), $350^{\circ}$ (Noroeste),

respectivamente.

Fotos: Denise Dias dos Santos, 30/06/2013. 


\section{RESULTADOS E DISCUSSÃO}

Por meio das análises dos dados registrados pela estação meteorológica, foi possível conhecer a distri- buição horária das precipitações no período 2007-2011 e também sazonal (verão, outono, inverno e primavera). Os gráficos abaixo (Figuras 3 e 4) comparam os valores percentuais verificados.

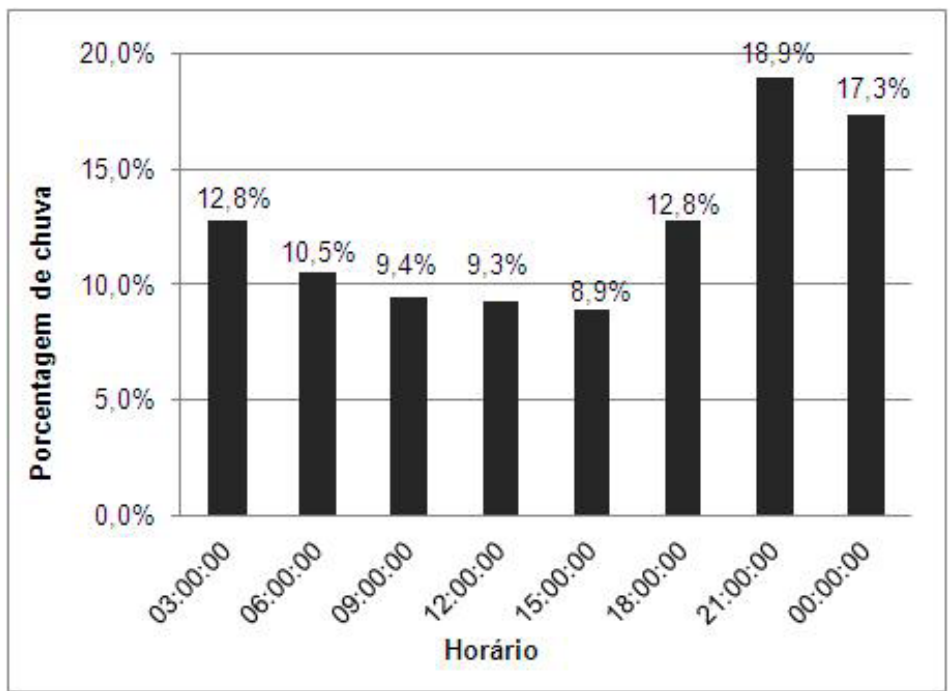

Figura 3: Distribuição percentual da chuva acumulada a cada três horas no período de 2007 a 2011.
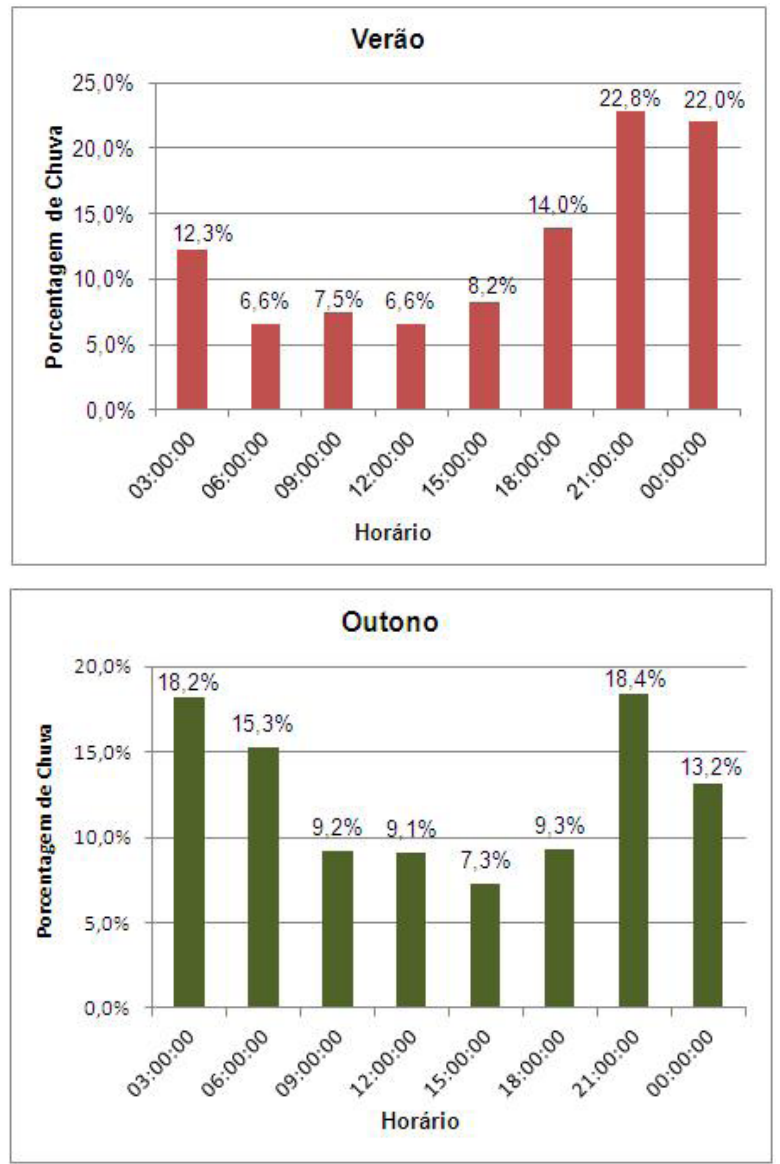
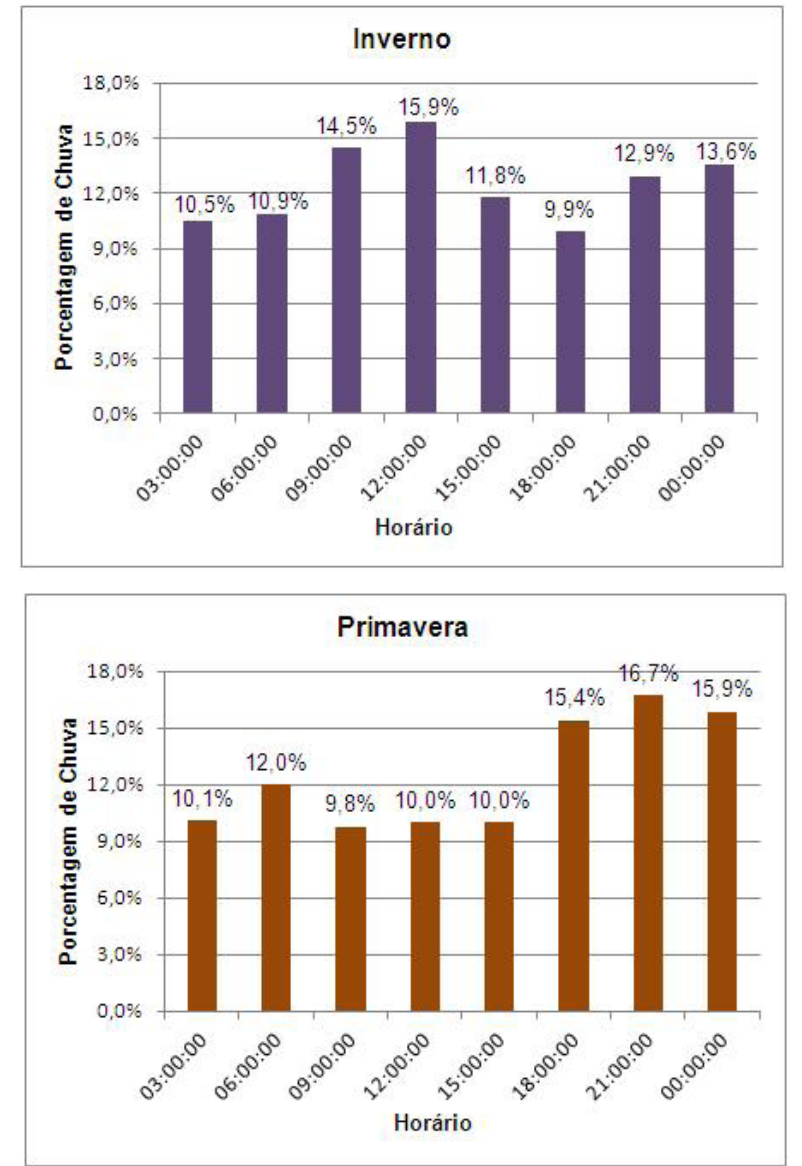

Figura 4: Distribuição percentual da chuva acumulada a cada três horas durante o verão, outono, inverno e primavera no período (2007 a 2011).

Fonte: Sinda, 2013. Org: Santos, 2013. 


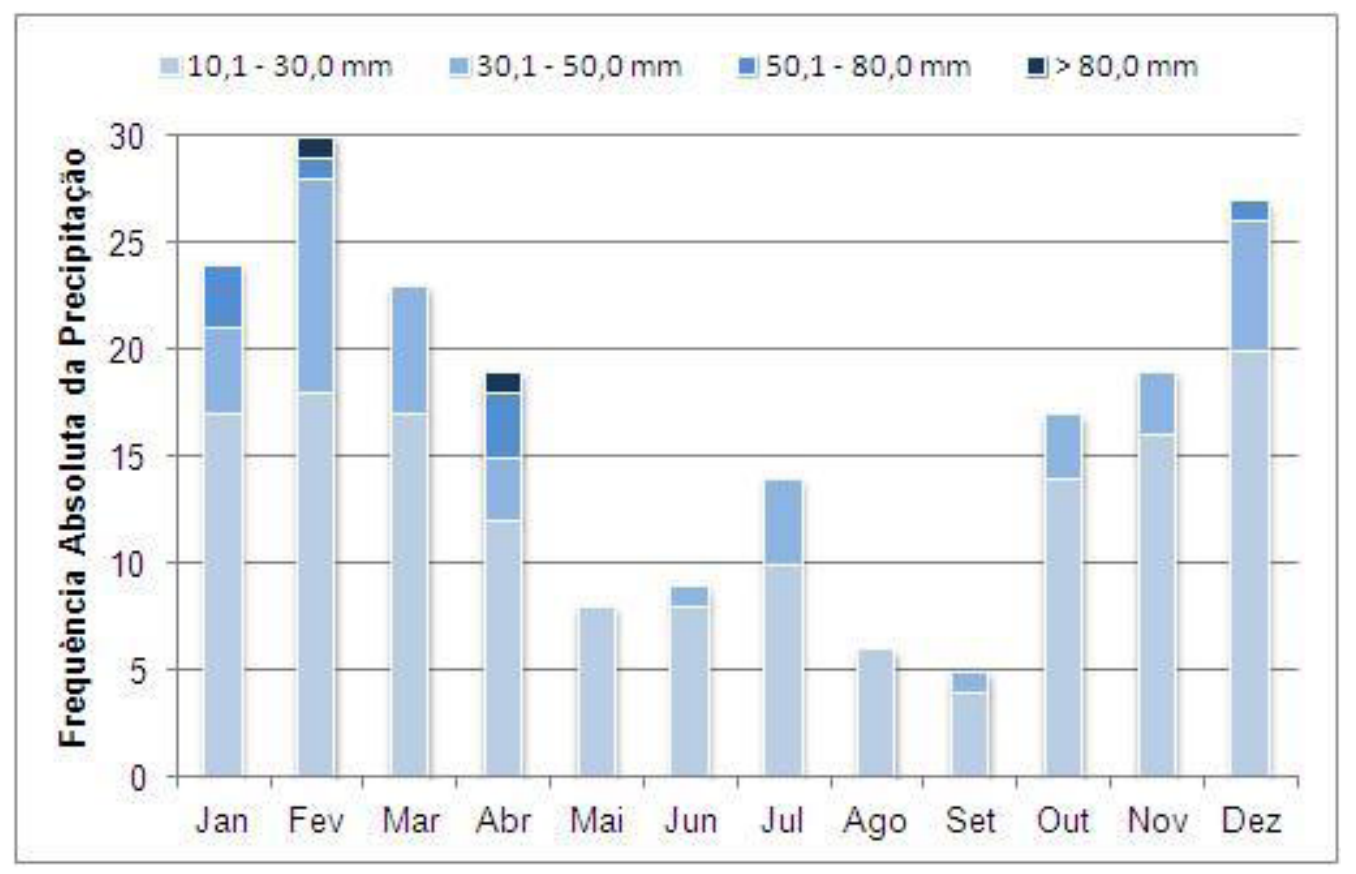

Figura 5: Frequência das precipitações no período 2007-2011.

Fonte: Sinda, 2013. Org: Santos, 2013.

Foram determinados também intervalos de classes para a frequência das precipitações no período estudado (Figura 5). As precipitações no intervalo de 10 a $20 \mathrm{~mm}$ foram as mais frequentes em todos os meses, assim como no intervalo de 20,1 a $40 \mathrm{~mm}$; contudo, as precipitações em ambos os intervalos são mais evidentes nos meses de janeiro, fevereiro e dezembro, o que leva à conclusão que no verão (estação mais chuvosa), a pluviosidade mensal se distribui entre 10 a $40 \mathrm{~mm}$. Acima desses valores, os eventos podem ser caracterizados como "extremos", pois ocorrem fora do intervalo onde há precipitações mais frequentes (de 10 a $40 \mathrm{~mm}$ ). A partir destes resultados, eles serão analisados.

Os eventos considerados como extremos desenvolvem-se principalmente no período primavera-verão, onde a atividade convectiva torna-se mais atuante devido ao maior aquecimento da atmosfera e evaporação da água do oceano. Este fato justifica a observação de Silva et al (2005) que nos meses de verão se registram os maiores números de eventos de escorregamentos e inundações nos municípios do Litoral Norte, conforme registros da Defesa Civil. Durante o período estudado o mês de julho é o que apresenta o maior número de eventos de precipitação no inverno, comparado aos meses de junho e agosto; esses eventos são consequências dos sistemas frontais que se originam na Argentina ou no Sul do Brasil e avançam para o Sudeste brasileiro. Segundo Tarifa (1975), a combinação de diferentes tipos de fluxos polares e suas consequentes cadeias de tipos de tempo permite o surgimento de condições temporais para a precipitação em diferentes graus de intensidade acima ou abaixo do que foi considerado habitual.

\subsection{Evento extremo do dia 11 de fevereiro de 2007}

No primeiro ano da série estudada (2007), ocorreu um evento de precipitação diária acima de $80,0 \mathrm{~mm}$ no dia 11 de fevereiro. As imagens de satélite Goes 12 (Figura 6) corroboram os dados coletados pela estação meteorológica no município.

Neste período do ano (verão), é comum as chuvas serem condicionadas à atuação da Zona de Convergência do Atlântico Sul (ZCAS), fenômeno atmosférico caracterizado pela elevada umidade localizada entre a Amazônia e o Sudeste brasileiro, causando precipitação nesta área. Segundo o Boletim Climanálise (CPTEC/ INPE), "as chuvas (do mês de fevereiro, no Sudeste) estiveram associadas principalmente aos episódios de ZCAS e aos vórtices ciclônicos em altos níveis que se configuraram sobre o leste da Região e áreas oceânicas adjacentes". O segundo sistema frontal que atuou no Brasil foi o responsável pelo evento do dia 11 de fevereiro em Caraguatatuba, contabilizando $98,5 \mathrm{~mm}$ de chuva (Figura 7), atuando em conjunto com o desenvolvimento do segundo evento de ZCAS no mês. Em um estudo de eventos extremos no Sudeste Brasileiro no período 1997-2001, Satyamurty e Santo (2002) definem que características da circulação regional apontam para a atuação do ZCAS nos meses de verão e primavera, quando observaram também que o maior número de episódios extremos ocorreu neste período. 

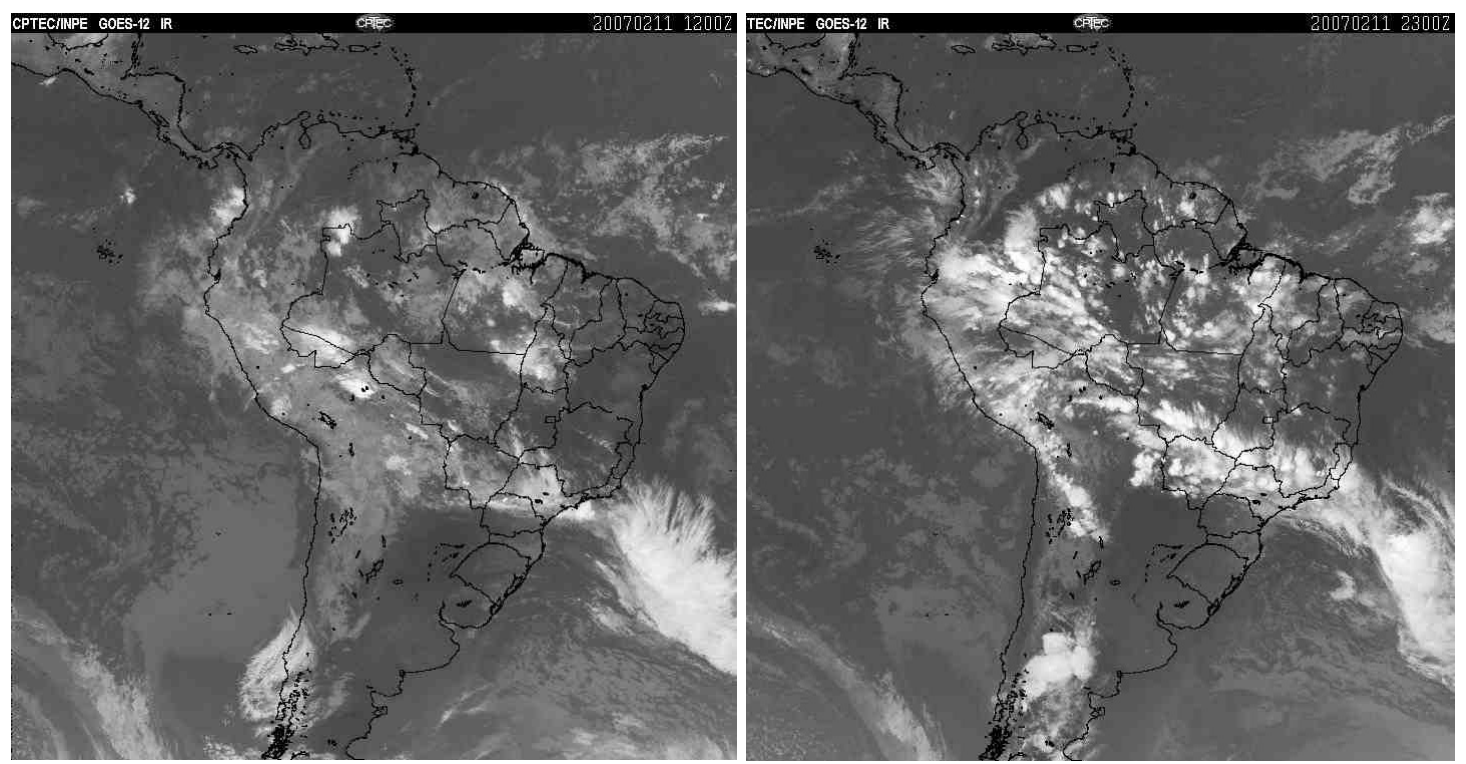

Figura 6: Imagens do satélite Goes 12 da América do Sul para o dia 11/02/2007, 1200Z e 2300Z (9h00 e 20 h00 no horário de Brasília, respectivamente).

Fonte: DSA/INPE.

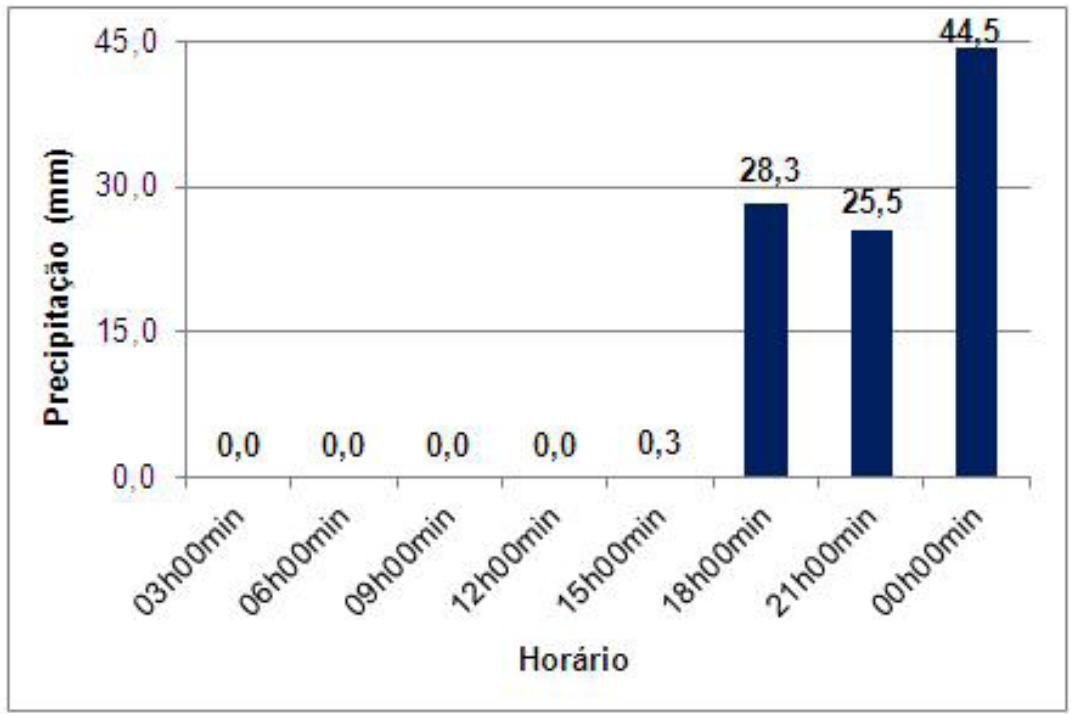

Figura 7: Distribuição horária da precipitação acumulada no dia 11 de fevereiro de 2007. Fonte: Sinda, 2013. Org: Santos, 2013.

\subsection{Eventos extremos do ano de 2008: 29 de janeiro e 26 de dezembro}

No mês de janeiro, o evento atmosférico que proporcionou as precipitações do dia 29 originou-se no sistema frontal formado na região Sul que se deslocou para o Sudeste, favorecendo a formação da ZCAS (Figura 8). Durante este mês, as precipitações registradas no estado de São Paulo obtiveram elevados valores e em Caraguatatuba, no dia 29, a chuva acumulada foi de $44,0 \mathrm{~mm}$ (Figura 9), distribuídos ao longo do dia e sendo mais intensa no final da tarde (das $15 \mathrm{~h} 00$ às $18 \mathrm{~h} 00$ ).

No mês de dezembro deste ano, a ZCAS já se mostrava atuante no início do mês, antes mesmo do começo da estação considerada mais chuvosa no centro-sul do Bra- sil. Na região estudada o evento diário mais significante ocorreu ao final do mês, no dia 26 (Figura 10), quando,.

"um centro de baixa pressão configurou-se a leste do Rio Grande do Sul, dando origem ao quinto sistema frontal no litoral de Torres-RS. Este sistema deslocou-se pelo oceano até a altura do Estado de São Paulo, contribuindo para a formação do terceiro episódio de ZCAS a partir do dia 25". (CPTEC/INPE, 2008).

A atuação da ZCAS, aliada às condições regionais, foi mais expressiva no município de Ubatuba, onde o acumulado diário foi de 97,4 mm, enquanto em Caraguatatuba o valor foi de 55,8 mm (Figura 11). 


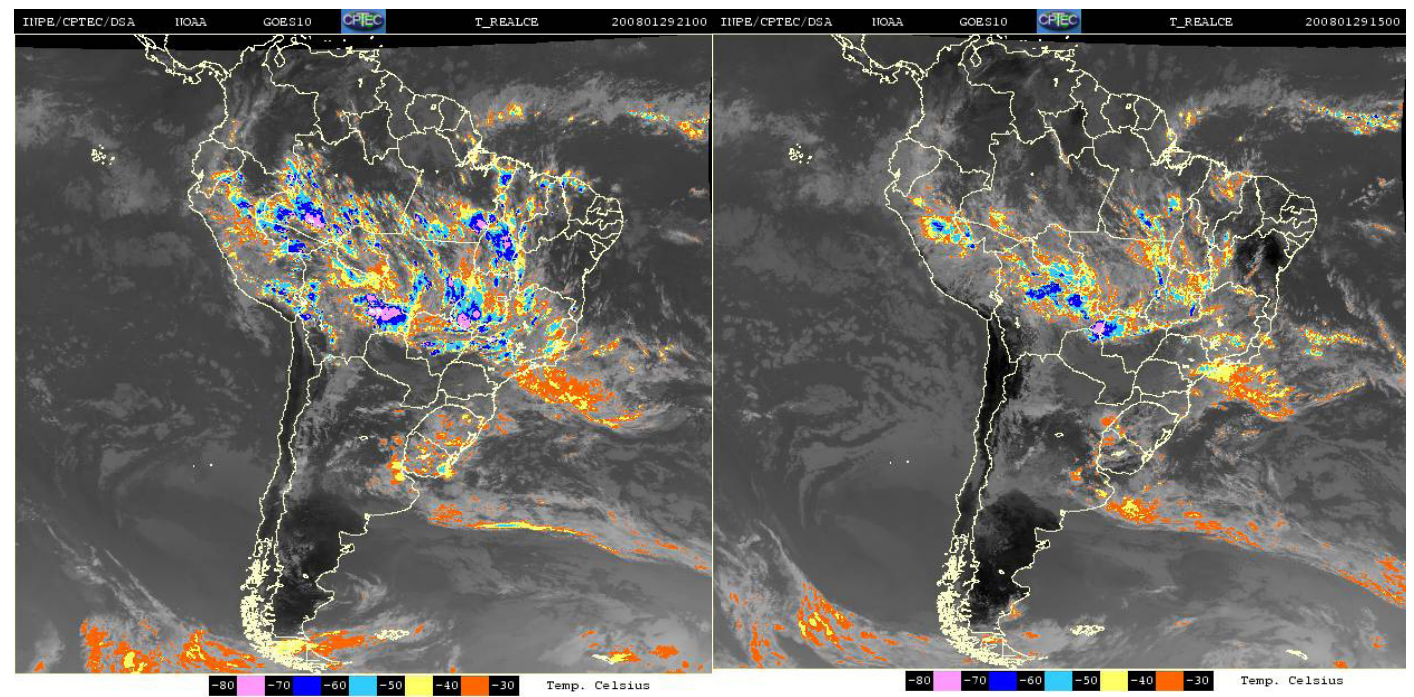

Figura 8: Imagens do satélite Goes 10 da América do Sul para o dia 29/01/2008, 1500Z e 2100Z (12h00 e 18h00 no horário de Brasília, respectivamente). Fonte: DSA/INPE.

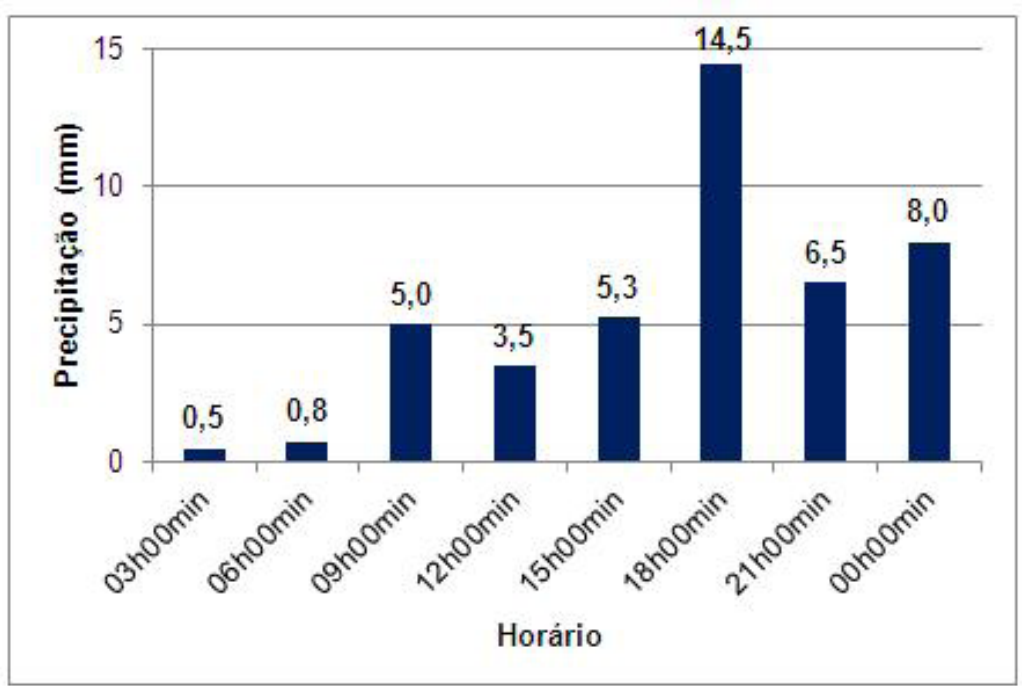

Figura 9: Distribuição horária da precipitação acumulada no dia 29 de janeiro de 2008. Fonte: Sinda, 2013. Org: Santos, 2013.
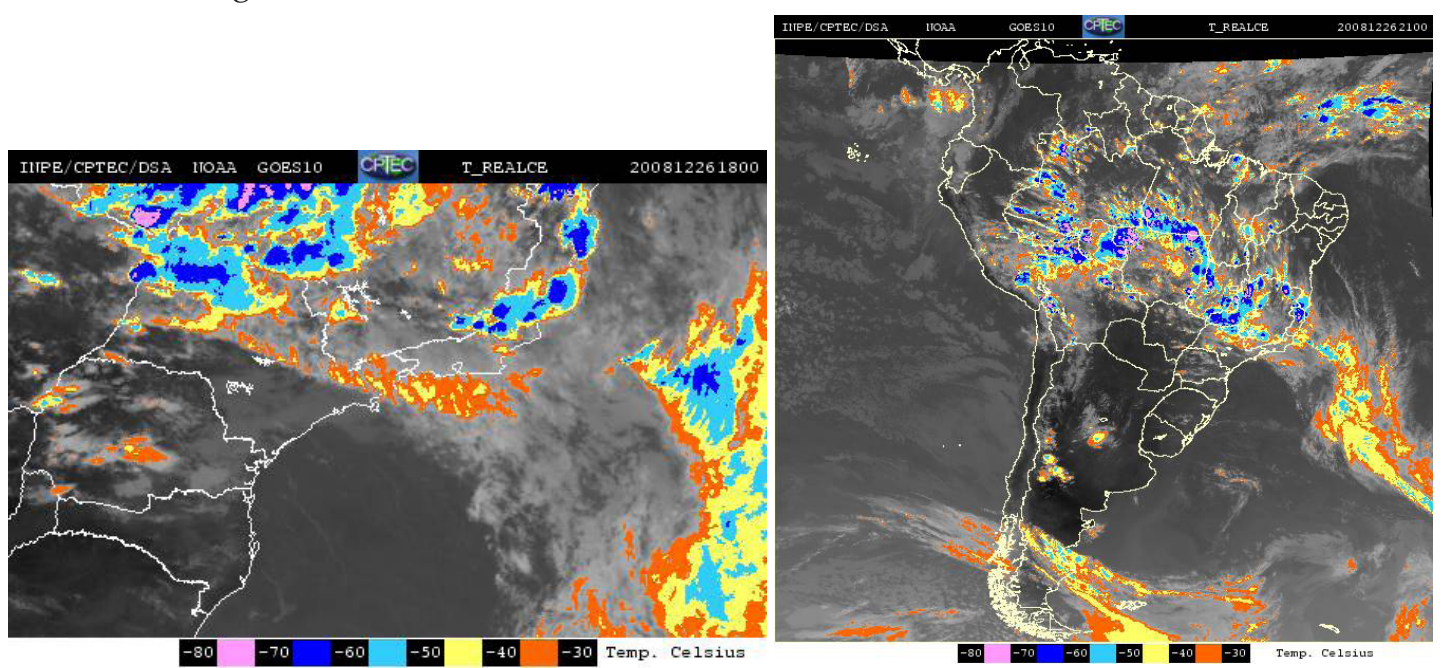

Figura 10: Imagens do satélite Goes 10 dos estados de São Paulo e Rio de Janeiro, e América do Sul para o dia 26/12/2008, 1800Z e 2100Z (15h00 e 18h00 no horário de Brasília, respectivamente). Fonte: DSA/INPE. 


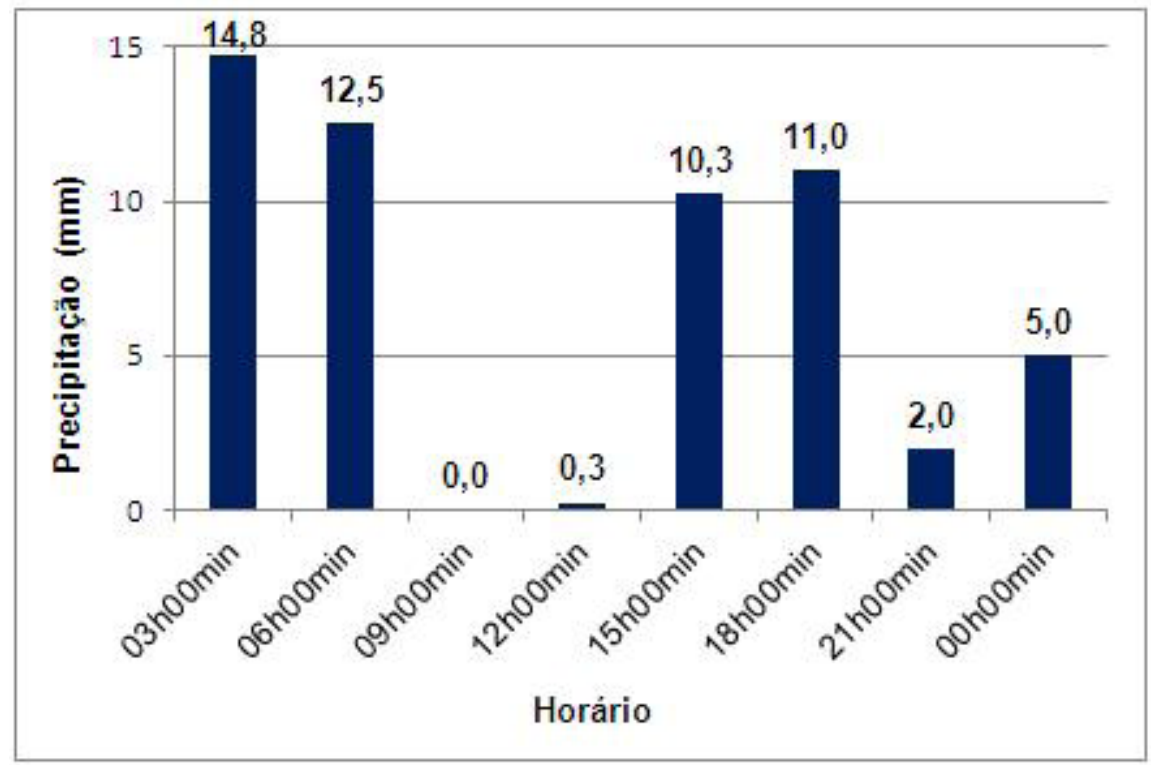

Figura 11: Distribuição horária da precipitação acumulada no dia 26 de dezembro de 2008. Fonte: Sinda, 2013. Org: Santos, 2013.

\subsection{Eventos extremos do ano de 2009: 21 de abril e 28 de dezembro}

No ano de 2009 foram analisados dois eventos de precipitação diária intensa. O primeiro, registrado em 21 de abril com de 106,0 mm, ocorreu por consequência de resquícios de um sistema frontal, aliado às condições locais (orografia e umidade proveniente do oceano), que intensificou a formação de áreas de instabilidade (Figuras 12 e 13). A chuva teve início e intensificou-se durante a madrugada e no fim da manhã, diminuindo gradativamente no final da tarde e início da noite (Figura 14). Neste período do ano (outono) as chuvas convectivas tendem a diminuir e os sistemas frontais são os principais responsáveis pela precipitação no litoral paulista. Dosewell et al. (1996) apud Satyamurty e Santo (2002) "apontam para o movimento lento do sistema como um fator importante para um sistema convectivo se tornar um caso extremo de chuva".

O segundo evento ocorreu no dia 28 de dezembro,
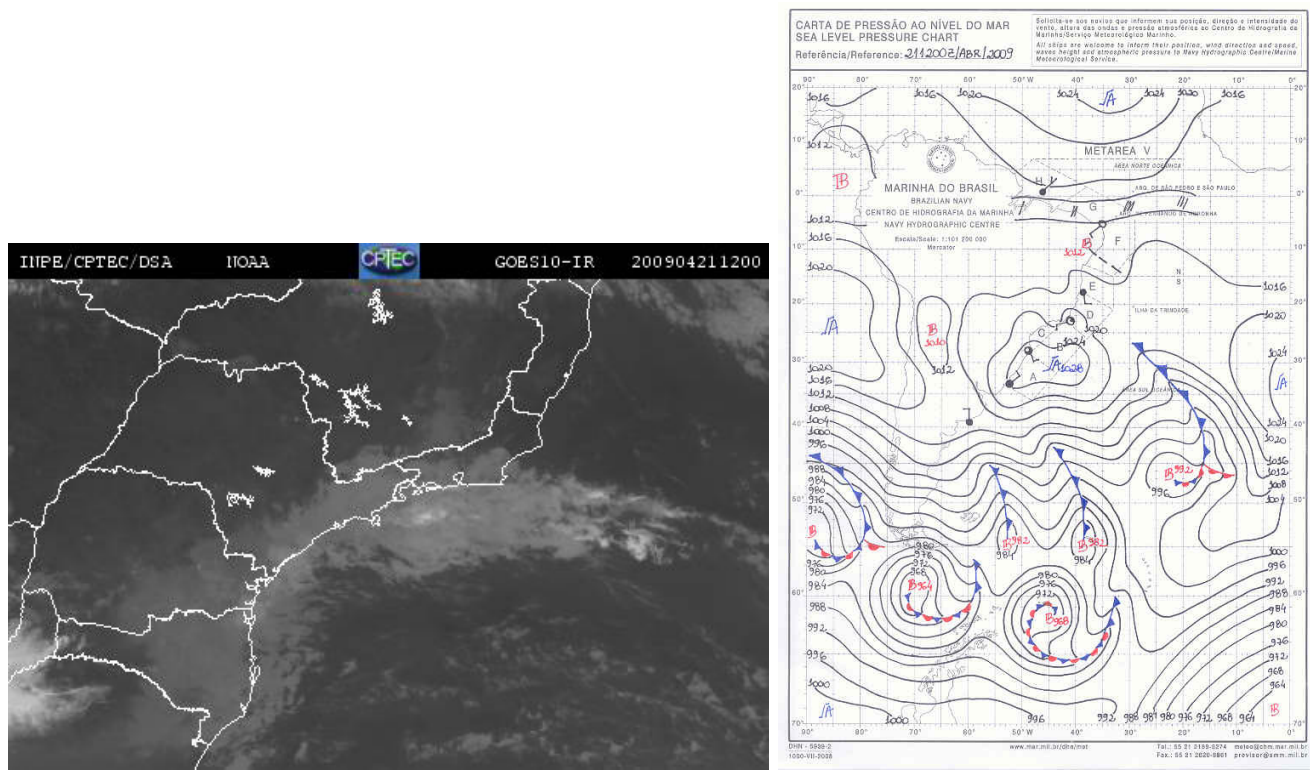

Figuras 12 e 13: Imagem do satélite Goes 10 dos estados de São Paulo e Rio de Janeiro, para o dia 21/04/2009, 1200Z (9h00 no horário de Brasília). Fonte: DSA/INPE; Carta sinótica para o dia 21/04/2009.

Fonte: Marinha do Brasil. 


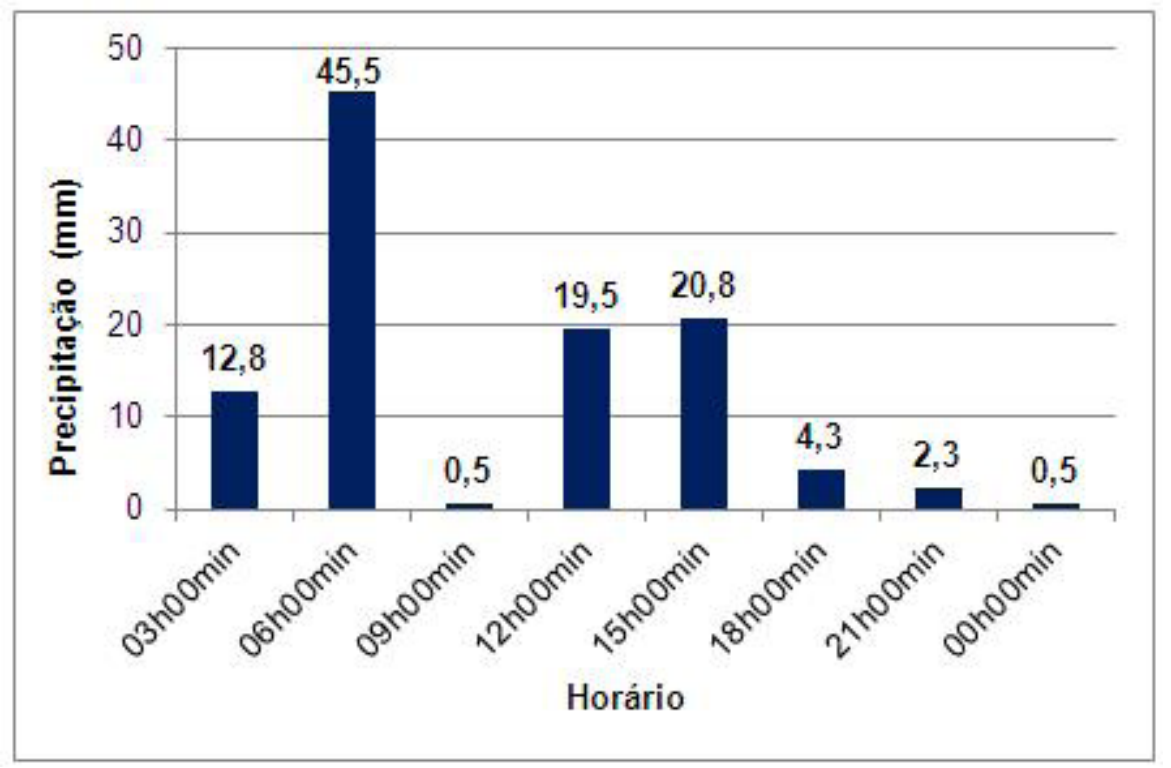

Figura 14: Distribuição horária da precipitação acumulada no dia 21 de abril de 2009.

Fonte: Sinda, 2013. Org: Santos, 2013

com 69,3 mm registrados (Figura 15), foi consequência de uma massa de ar úmida e instável aliada uma área de baixa pressão nas proximidades dos Estados de São Paulo e Rio de Janeiro, intensificando o surgimento de alta convergência e forte precipitação, causando danos materiais principalmente no Vale do Paraíba e litoral fluminense (CPTEC/INPE, 2009). Durante o verão as precipitações são, em sua maioria, resultado da convecção e formação de nebulosidade, que provocam chuvas principalmente no final da tarde e início da noite (Figura 16).

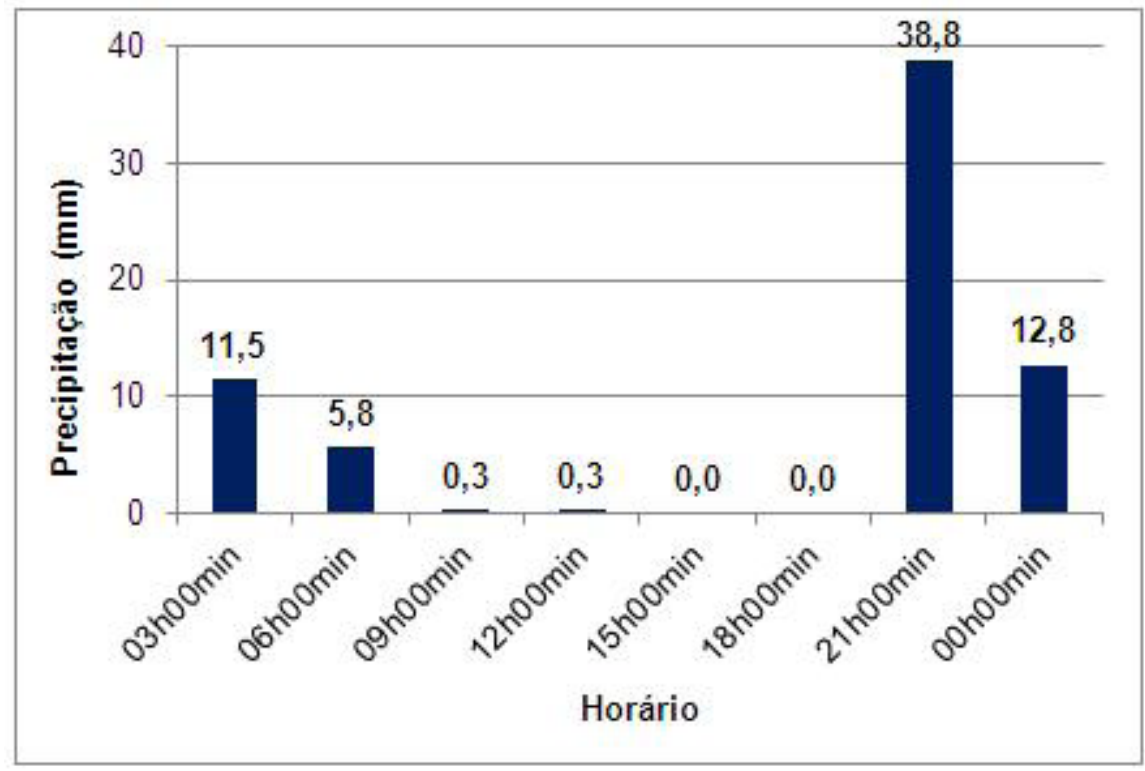

Figura 15: Distribuição horária da precipitação acumulada no dia 28 de dezembro de 2009. Fonte: Sinda, 2013. Org: Santos, 2013. 

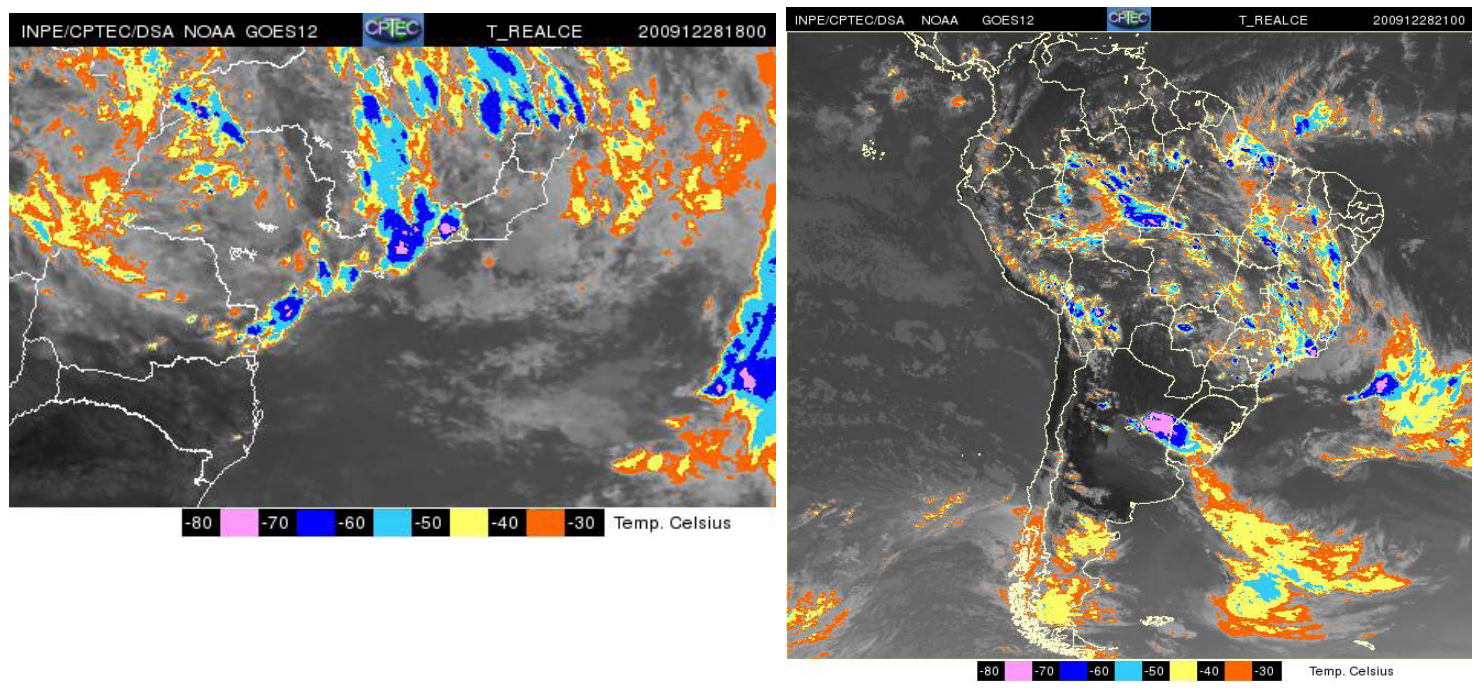

Figura 16: Imagens do satélite Goes 12 da América do Sul para o dia 28/12/2009, 1800Z e 2100Z (15h00 e 18 h00 no horário de Brasília, respectivamente).

Fonte: DSA/INPE.

\subsection{Eventos extremos do ano de 2010: 25 de fevereiro e 05 de abril}

Segundo o Boletim Climanálise, do CPTEC/INPE, o mês de fevereiro no ano de 2010 foi caracterizado pela ausência de episódios de ZCAS, muito comuns nesta época do ano. Em Caraguatatuba, as precipitações mais relevantes neste mês ocorreram no dia 25 , durante o período da tarde, com o acúmulo de $59,5 \mathrm{~mm}$ ao final do dia (Figura 17). Aqui, a chuva foi resultado de uma região de convergência de umidade, aliada ao quarto sistema frontal que atingiu o país no final do mês de fevereiro (Figura 18).

As chuvas do dia 5 de abril deste ano, que resultaram em 76,0 mm registrados na área de estudo (Figura 19), foram provocadas pelo primeiro sistema frontal que adentrou o país neste mês (Figura 20); o sistema avançou até o sul do estado da Bahia. Como característica de sistemas frontais, nesta data as precipitações se distribuíram ao longo do dia, conforme a velocidade e intensidade do sistema, e as chuvas foram predominantes na madrugada e pela manhã.

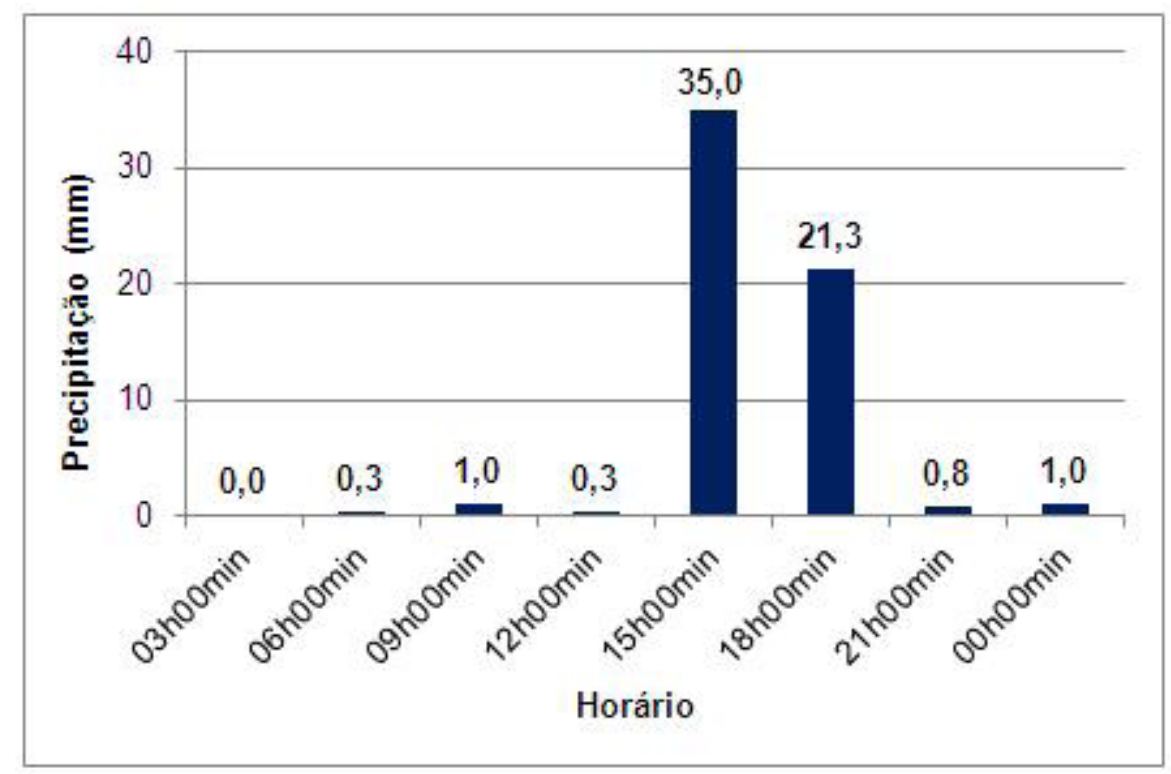

Figura 17: Distribuição horária da precipitação acumulada no dia 25 de fevereiro de 2010. Fonte: Sinda, 2013. Org: Santos, 2013. 

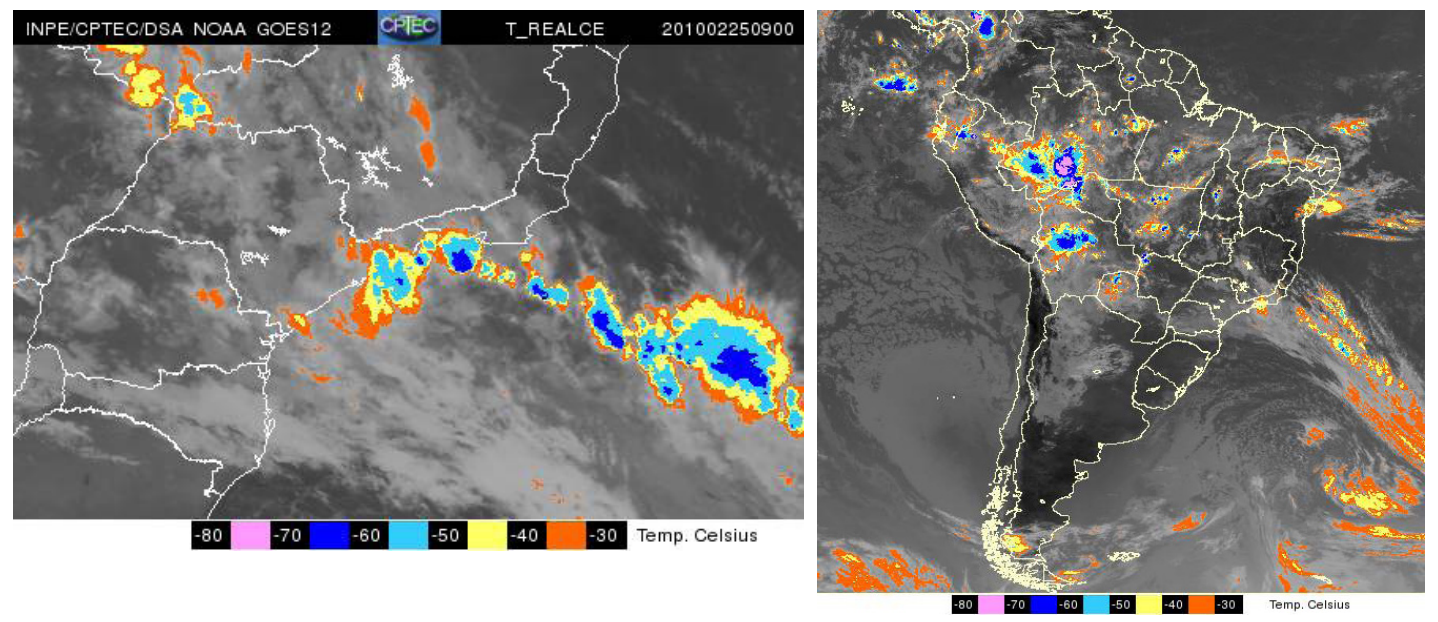

Figura 18: Imagens do satélite Goes 12 dos estados de São Paulo e Rio de Janeiro e América do Sul para o dia 25/02/2010, 0900Z e 1500Z (6h00 e 12h00 no horário de Brasília, respectivamente). Fonte: DSA/INPE

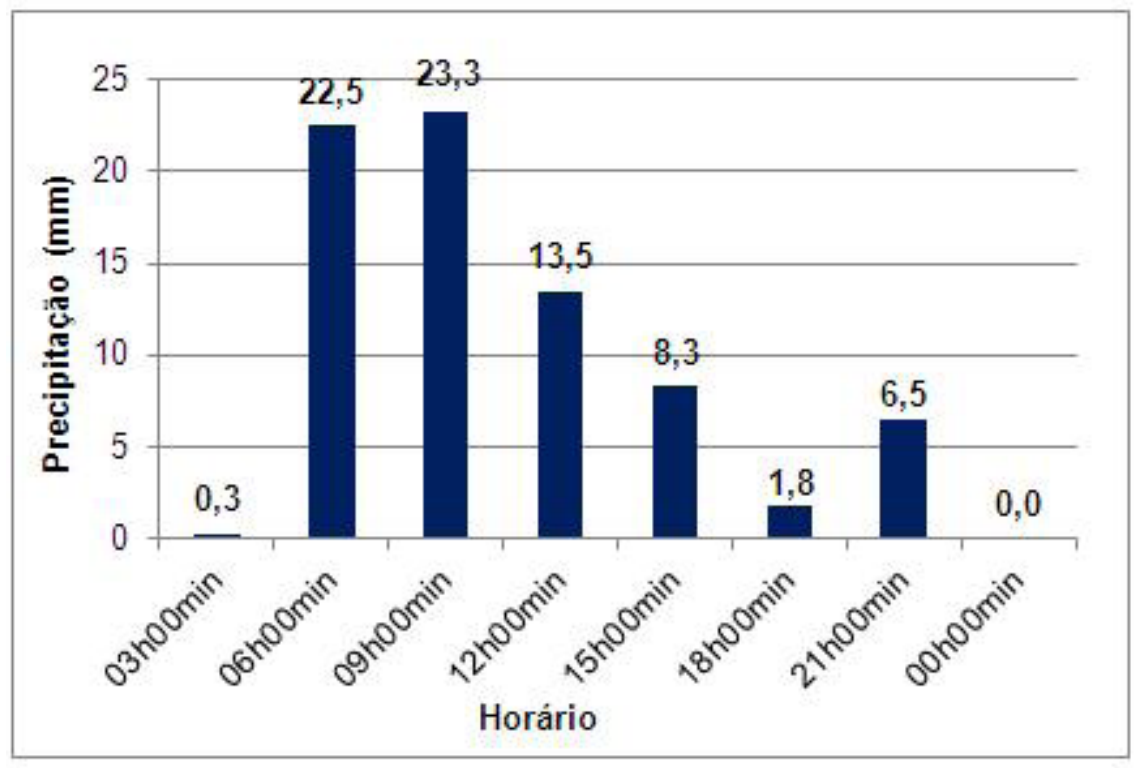

Figura 19: Distribuição horária da precipitação acumulada no dia 05 de abril de 2010. Fonte: Sinda, 2013. Org: Santos, 2013.
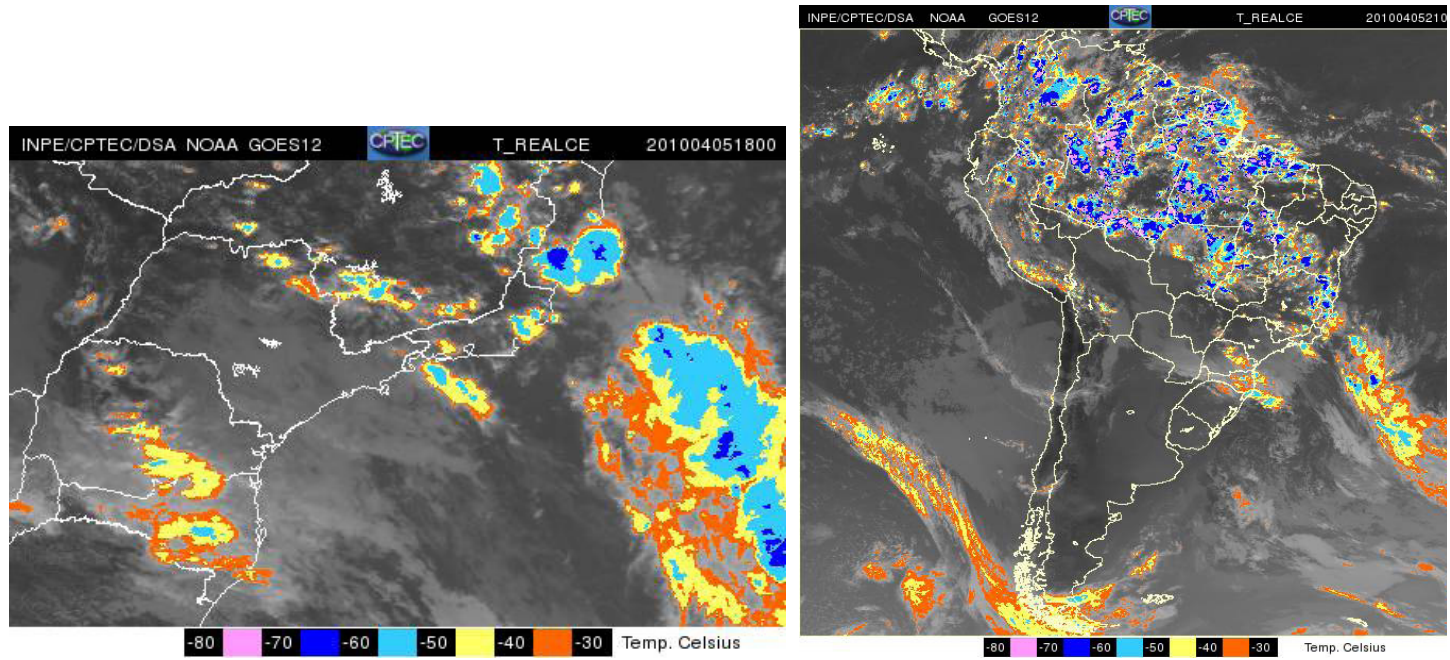

Figura 20: Imagens do satélite Goes 12 dos estados de São Paulo e Rio de Janeiro para o dia 05/04/2010, 1800Z e $2100 Z$ (15h00 e 18 h00 no horário de Brasília, respectivamente). Fonte: DSA/INPE. 


\subsection{Eventos extremos do ano de 2011: 11 de janeiro e 24 de abril}

Em janeiro, a atuação de episódios de ZCAS, associada às temperaturas da superfície do mar acima da média em parte da costa da Região Sudeste (CPTEC/ INPE, 2011), contribuíram para grande volume de chuva registrado na região, de origem exclusivamente convectiva (os sistemas frontais que atuaram durante o mês de janeiro não avançaram sobre o Sudeste, Figuras 21 e 22). Durante estes episódios, em Caraguatatuba o maior valor de precipitação registrado para o mês foi de 54,8 $\mathrm{mm}$ no dia 11 de janeiro (Figura 23).

Durante o mês de abril, os sistemas frontais foram responsáveis pelas chuvas no Sudeste do Brasil. Os 54,5 $\mathrm{mm}$ registrados no dia 24 de abril em Caraguatatuba ocorreram durante a passagem do quarto sistema frontal atuante no mês, cuja atuação se deu com mais ênfase na região Sul, porém ao deslocar-se para o oceano, no Sudeste, favoreceu a formação de área de instabilidade no litoral norte paulista (Figuras 24 e 25).
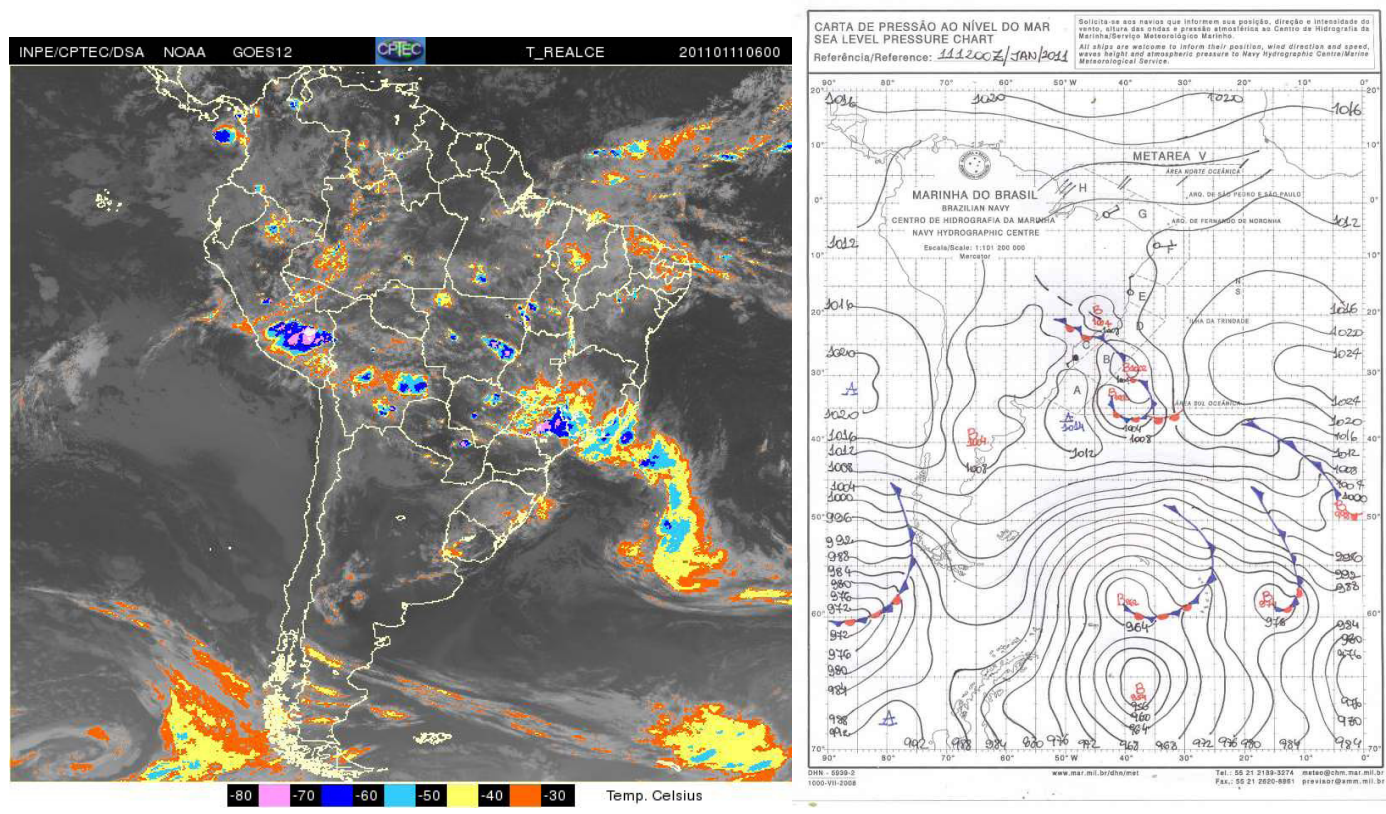

Figuras 21 e 22: Imagem do satélite Goes 12 da América do Sul para o dia 11/01/2011, 0600Z (03h00 no horário de Brasília,). Fonte: DSA/INPE; Carta sinótica para o dia 11/01/2011. Fonte: Marinha do Brasil.

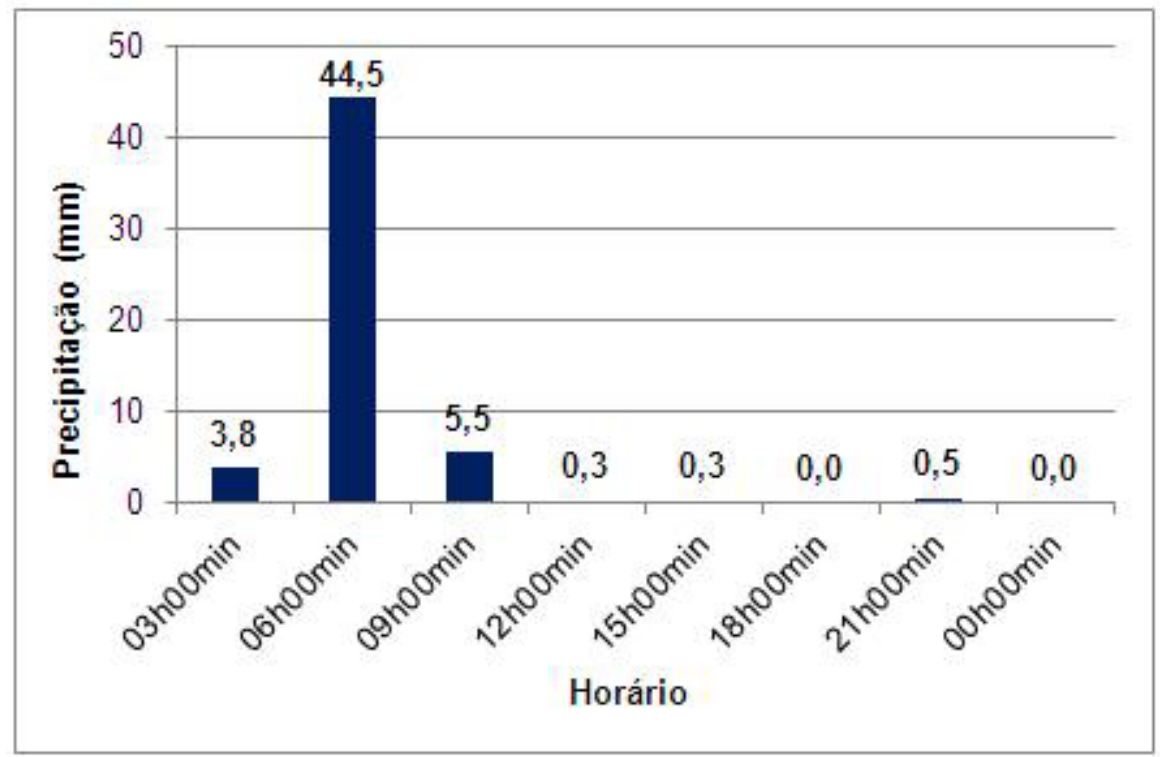

Figura 23: Distribuição horária da precipitação acumulada no dia 11 de janeiro de 2011. Fonte: Sinda, 2013. Org: Santos, 2013. 


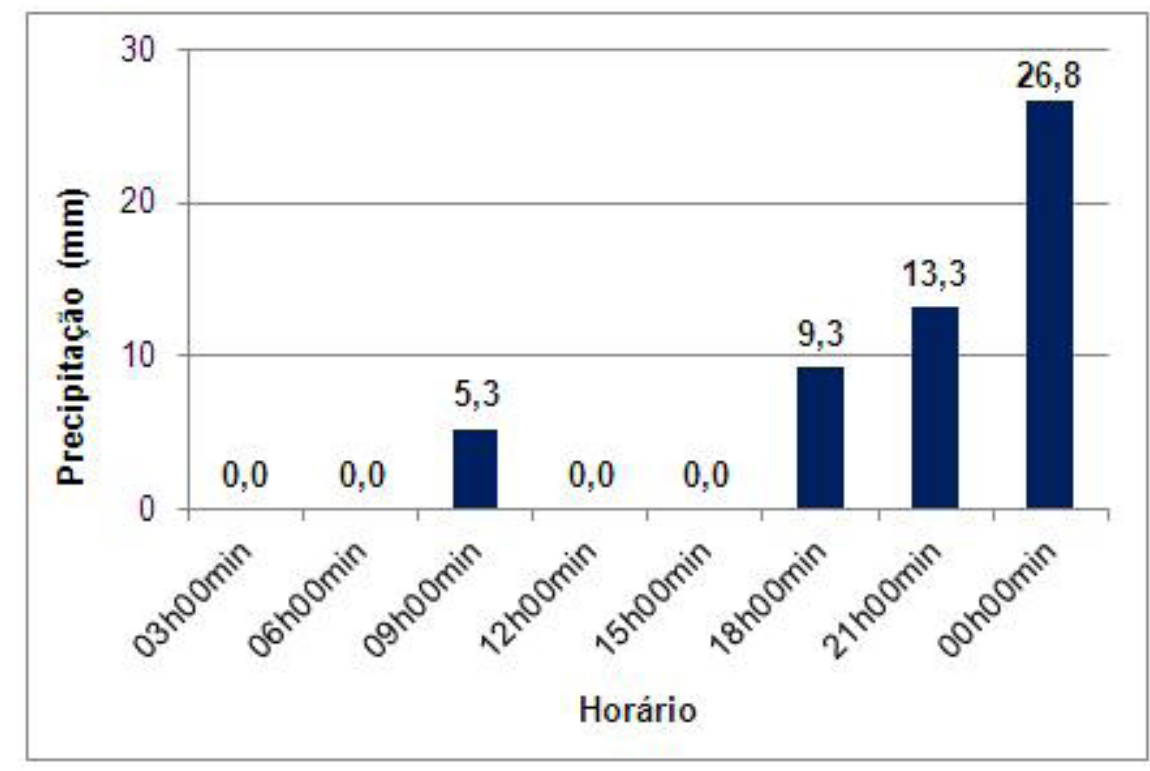

Figura 24: Distribuição horária da precipitação acumulada no dia 24 de abril de 2011. Fonte: Sinda, 2013. Org: Santos, 2013.
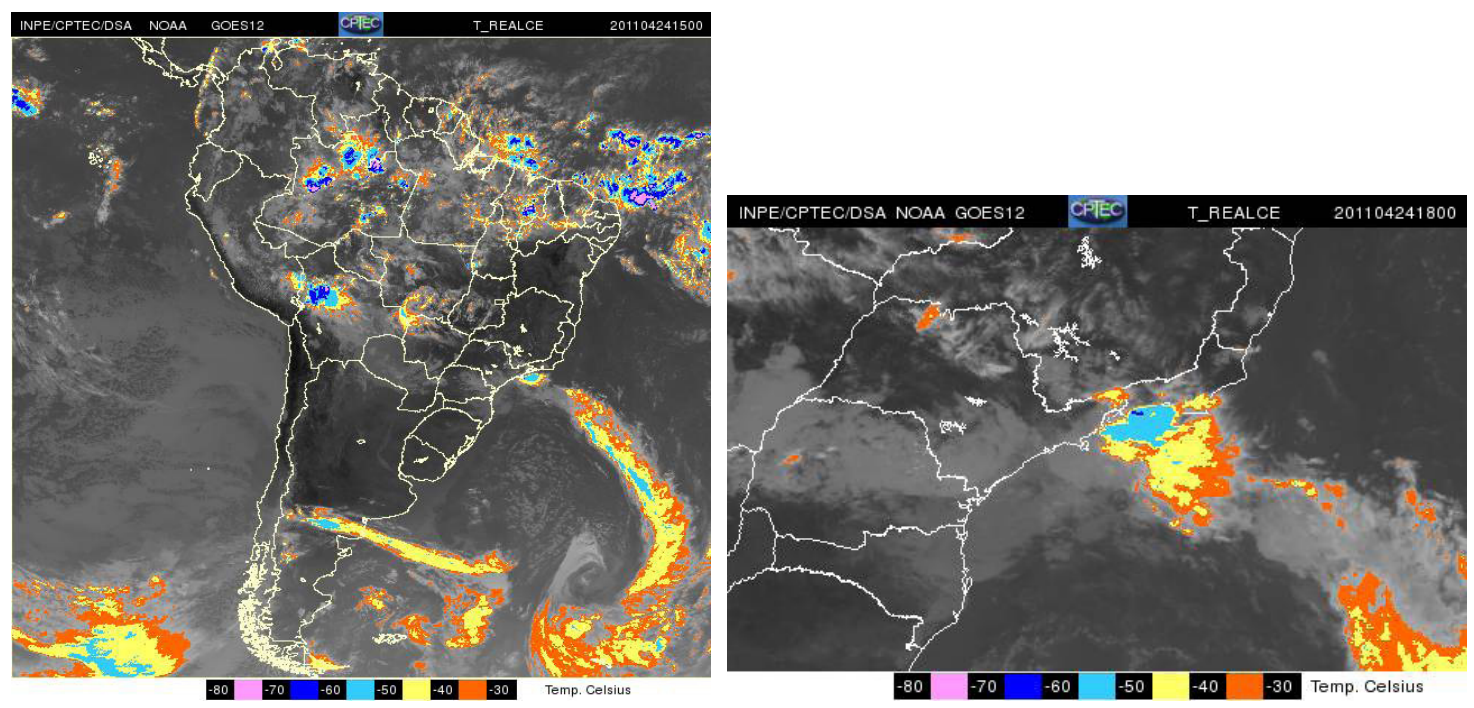

Figura 25: Imagens do satélite Goes 12 dos estados de São Paulo e Rio de Janeiro para o dia 24/04/2011, 1500Z e $1800 \mathrm{Z}$ (12h00 e 15h00 no horário de Brasília, respectivamente). Fonte: DSA/INPE.

Segundo Armani e Galvani (2011), durante o verão pode ocorrer formação uma extensa área de nebulosidade, desde a Amazônia até o centro-sul do país, que associada a um escoamento convergente de umidade é responsável por grande parte das precipitações na área que abrange; este fenômeno é conhecido como Zona de Convergência do Atlântico Sul (ZCAS). Assim, é importante ressaltar que os eventos ocorridos nos verões do período estudado foram influenciados pelas ZCAS; estas tiveram a contribuição, também, do sistema frontal que se deslocava pela região (exceto no ano de 2010, onde o evento estudado desenvolveu-se apenas pela chegada do sistema frontal, sem contribuir para a ZCAS). De acordo com os autores, a intensificação dos sistemas frontais nesta época do ano contribui para a formação da ZCAS. As análises aqui desenvolvidas e os resultados obtidos aproximam-se dos estudos feitos por Alves e Galvani (2012) que, analisando a ocorrência horária e sazonal das precipitações no município de São Paulo, também observaram que os totais pluviométricos são mais concentrados no final da tarde durante o verão.

De acordo com Borsato e Souza Filho (2008) "As chuvas frontais, mais intensas ou mais escassas, estão relacionadas com as intensidades e as trajetórias dos sistemas frontais", confirmando a distribuição das chuvas durante o outono e o inverno, condicionada à passagem de sistemas frontais. Como já citado anteriormente, a umidade oferecida pelo oceano em conjunto com os sistemas atmosféricos atuantes não permitem que o 
município tenha uma estação totalmente seca. Mesmo com a ausência da atuação de sistemas frontais relevantes, há registros de precipitação durante o outono e também no inverno.

\section{CONCLUSÕES}

No verão, as chuvas tendem a concentrar-se no final da tarde e início da noite, devido à influência da convecção térmica e a formação de nebulosidade, aliada à configuração do relevo que propicia maiores precipitações. No outono, as chuvas estão condicionadas ao deslocamento dos sistemas frontais, resultando em precipitações melhor distribuídas ao longo das horas do dia.

Dentre os nove eventos aqui analisados, seis ocorreram durante o verão e três durante o outono. Percebe-se que, no período estudado, assim como o verão é considerada a estação com maior volume de precipitações, também é no verão que ocorrem os maiores valores de chuvas diários. Isso se deve porque nesta estação predominam os sistemas de baixa pressão, responsáveis pela formação de áreas de instabilidade atmosférica. Os eventos de outono foram condicionados à intensidade e duração da passagem de sistemas frontais.

\section{REFERÊNCIAS}

ALVES, R.R.; GALVANI, E. Ocorrência horária e sazonal das precipitações no município de São Paulo, SP. GEONORTE - Revista Eletrônica do Departamento de Geografia da UFAM, v. 5, p. 530540, 2012.

ARMANI, G.; GALVANI, E. Fluxos polares e o ritmo dos sistemas atmosféricos no nordeste do Estado de São Paulo. Soc. nat. (Online), Uberlandia, v. 23, n. 1, 2011. Available from <http://www. scielo.br/scielo.php?script=sci_arttext\&pid=S1982$45132011000100002 \& \operatorname{lng}=\mathrm{en} \& \mathrm{nrm}=\mathrm{iso}>$. Acesso em 21 Abril 2014. http://dx.doi.org/10.1590/S198245132011000100002.

BORSATO, V. A. ; SOUZA FILHO, E. E. . A Dinâmica Atmosférica na vertente oriental da bacia do alto rio Paraná e a gênese das chuvas. Acta Scientiarum. Technology, v. 30, p. 221-229, 2008.

BORSATO, V. A. . A Dinâmica Atmosférica no CentroSul do Brasil no Verão e as Influências do El Niño Oscilação Sul (ENOS). Revista do Departamento de Geografia - USP, v. 22, p. 135-157, 2011.

Cavalcanti, I. F. A. . Large scale and synoptic features associated with extreme precipitation over South America: A review and case studies for the first decade of the 21st century. Atmospheric Research (Print), v. 118, p. 27-40, 2012. Available from <http://www.sciencedirect.com/science/article/pii/ S0169809512001871> Acesso em 17 Nov. 2013. http://dx.doi.org/10.1016/j.atmosres.2012.06.012.

CONTI, J.B. Circulação secundária e efeito orográfico na gênese das chuvas na região lesnordeste paulista. Tese (Doutorado). Instituto de Geografia, Universidade de São Paulo, São Paulo, 1975.

CRUZ, O. A Serra do Mar e a Preservação de suas vertentes. Revista Orientação, São Paulo, n. 7, p. 39-45, 1986.

GALVANI, E. ; PEREIRA, A. R. ; KLOSOWSKI, E. S.. Relações entre o Índice de Oscilação Sul (IOS) e o total mensal de chuva em Maringá-PR. Acta Scientiarum (UEM) (Cessou em 2002), Maringá-Pr, v. 20, n.4, p. 531-535, 1998.

NUNES, L.H. Estudo da normalidade da pluviometria no setor serrano de Cubatão e Baixada Santista-SP. Revista do Departamento de Geografia, São Paulo, n.6, p. 31-43, 1992.

PEZZOPANE, J.E.M. et al . Caracterização da chuva horária em três locais do Estado de São Paulo: um subsídio ao planejamento de operações agrícolas de campo. Sci. agric., Piracicaba , v. 52, n. 1, Apr. 1995. Available from <http://www. scielo.br/scielo.php?script=sci_arttext\&pid=S0103$90161995000100013 \& \operatorname{lng}=\mathrm{en} \& \mathrm{n} r \mathrm{~m}=\mathrm{iso}>$. Acesso em 21 Apr. 2014. http://dx.doi.org/10.1590/S010390161995000100013.

SANT'ANNA NETO, J. L. Ritmo climático e a gênese das chuvas na zona costeira paulista. Dissertação (mestrado). Faculdade de Filosofia, Letras e Ciências Humanas, Universidade de São Paulo, São Paulo, 1990.

A climatologia geográfica no Brasil: origem e contexto histórico. In: Amorim, Sant'anna Neto \& Monteiro (orgs.). Climatologia urbana e regional: questões teóricas e estudos de caso. São Paulo: Outras Expressões, 2013, p. 11-73.

SANTOS, D. D. ; GALVANI, E. . Análise da Ocorrência Sazonal e Horária das Precipitações no Município de Caraguatatuba, SP. XV Simpósio Brasileiro de Geografia Física Aplicada, 2013, Vitória, ES. Vitória: Universidade Federal do Espírito Santo - UFES, 2013. v. 15. p. 10-18.

SATYAMURTY P.; SANTO, C. M. E. . Eventos Extremos de Precipitação na Região Sudeste do 
Brasil e redondezas no período de 1997-2001. In: XII Congresso Brasileiro de Meteorologia, 2002, Foz do Iguaçu, PR. Anais do XII Congresso de Meteorologia, 2002.

SENTELHAS, P. C. ; CRUCIANI, D. E. ; PEREIRA, A. S. ; NOVA, N. A. V. Distribuição horária de chuvas intensas de curta duração: um subsídio ao dimensionamento de projetos de drenagem superficial. Revista Brasileira de Meteorologia, Jaboticabal, v. 13, n.1, p. 45-52, 1998.

SILVA, A. C. ; SANT'ANNA NETO, J. L. ;

TOMMASELLI, J. T. G. ; TAVARES, R.

Caracterização das chuvas no litoral norte paulista. Cosmos, Presidente Prudente, v. 3, n.5, p. 39-48, 2005.

TARIFA, J. R. Fluxos polares e as chuvas de primavera-verão no estado de São Paulo. Tese (Doutorado). Instituto de Geografia, Universidade de São Paulo, São Paulo, 1975.

\section{CENTRO DE PREVISÃO DE TEMPO E ESTUDOS} CLIMÁTICOS (CPTEC/INPE). Boletim de Monitoramento e Análise Climática. Disponível em: < http://climanalise.cptec.inpe.br/ rclimanl/ boletim/index0112.shtml>. Acesso em 27 Jul. 2013.

CENTRO DE PESQUISAS METEOROLÓGICAS E CLIMÁTICAS APLICADAS À AGRICULTURA (CEPAGRI). Clima dos municípios paulistas. Disponível em: <http://www.cpa.unicamp.br/ outras-informacoes/clima-dos municipiospaulistas. html>. Acesso em: 27 de Jul. 2013.

DIRETORIA DE HIDROGRAFIA E NAVEGAÇÃO MARINHA DO BRASIL. Serviço Meteorológico Marinho. Disponível em: < http://www.mar.mil. $\mathrm{br} / \mathrm{dhn} / \mathrm{chm} / \mathrm{meteo} /$ index.htm $>$. Acesso em $27 \mathrm{Jul}$. 2013.

INSTITUTO BRASILEIRO DE GEOGRAFIA E ESTATÍSTICA (IBGE). Dados do Censo 2010 em Caraguatatuba/ SP. Disponível em: $<\mathrm{http} / / / w w w$. ibge.gov.br/cidadesat/topwindow.htm?1>. Acesso em: 16 Jan. 2013.

Google Earth. Coordenadas geográficas de Caraguatatuba/ SP. Acesso em: 16 Jan. 2013.

\section{SISTEMA NACIONAL DE DADOS AMBIENTAIS} (SINDA). Plataforma de Coleta de Dados. Disponível em: $<$ http://sinda.crn2.inpe.br/PCD/>. Acesso em: 04 Jan. 2013. 